\section{P46 THE INFLUENCE OF AGE AND GENDER ON ALLERGY TEST RESULTS: IMPLICATIONS FOR THE USE AS BIOMARKERS IN CHILDHOOD ASTHMA}

HRM Mohammad, DB Belgrave, KKH Harding, AS Simpson, AC Custovic. Institute of Inflammation and Repair, Centre for Respiratory Medicine and Allergy, University Hospital South Manchester NHS Foundation Trusts, Manchester, UK

\subsection{6/thoraxjnl-2014-206260.187}

Introduction Skin prick tests (SPTs) and measurement of allergen-specific serum (s) $\operatorname{IgE}$ are the main diagnostic tools for confirming atopy. Results of both tests are usually reported as dichotomous (sensitised/not sensitised), using arbitrary cut-offs which are the same across different ages and genders (SPT $>3$ $\mathrm{mm}, \operatorname{sigE}>0.35 \mathrm{kU} / \mathrm{L}$ ). We investigated the influence of age and gender on allergy test results as biomarkers of asthma during childhood.

Methods Children in a population-based birth cohort $(\mathrm{n}=$ 1051) were followed from birth to age 11 years. Information on asthma/wheeze (questionnaires), SPTs and sIgE to inhalant allergens (mite, cat, dog) were collected at ages 3, 5, 8 and 11 years. We investigated the association between quantitative atopy (sum of SPT mean wheal diameters [MWD]/titres of sIgE) and wheeze/asthma across ages and genders.

Results There was a significant association between the SPT $\mathrm{MWD} / \mathrm{s} \operatorname{IgE}$ titre and wheeze/asthma at all ages and for both genders. However, the strength of this association was age and gender-dependent. For SPTs, the strength of the association between MWD and asthma increased with increasing age (OR 1.14-1.20, $\mathrm{p}=0.002)$; we observed the opposite pattern for sIgE titre (OR $0.97-0.99, \mathrm{p}=0.04)$. For any given SPT/sIgE level, boys were significantly more likely to express clinical symptoms, particularly in early life; this difference between males and females appeared to diminish with age, and was no longer significant by age 11 years.

Conclusions Age and gender have to be taken into account when interpreting the results of allergy tests (skin tests and $\operatorname{IgE}$ measurement) in the context of asthma during childhood.

\section{P47 CONTINUOUS LARYNGOSCOPY DURING EXERCISE (CLE): A PRACTICAL AND VALUABLE TEST IN A RESPIRATORY SERVICE?}

B Panchasara, GS Haji, S Ward, A Menzies-Gow, JH Hull. Royal Brompton Hospital, London, UK

\subsection{6/thoraxjnl-2014-206260.188}

Introduction and rationale Exertional wheeze and dyspnoea are most frequently attributed to exercise induced bronchoconstriction (EIB), yet may arise secondarily to a temporary closure of the larynx. This condition, termed Exercise induced laryngeal obstruction (EILO), is best characterised by the gold standard technique of direct and continuous laryngoscopy during exercise (CLE). To date most descriptions of the utility of CLE are in young highly athletic populations.

Objectives Assessment of the safety, utility and application of CLE in subjects with unexplained and/or disproportionate exertional dyspnoea in a general respiratory population (i.e. not confined to athletes).

Methods and measurements Patients referred for CLE with unexplained breathlessness and other respiratory diagnosis including treatment refractory asthma and COPD were identified. Thereafter clinical and physiological assessments were reviewed.

Results In total 83 referrals (October 2012-February 2014) for CLE studies were analysed. The overall median (range) age was 43 (17-71) years. The majority of subjects were female $(\mathrm{n}=$ $56)$. Only a total of $4(5 \%)$ subjects were athletes. We made a diagnosis of EILO in 30 (36\%) of subjects studied. Prior to CLE $32(39 \%)$ had been given a diagnosis of EIB, and of these we identified 17 (53\%) actually had a diagnosis of EILO. Only one minor complication (pre-syncopal episode) was encountered during the procedure.

Conclusion CLE is a safe effective method for the assessment of disproportionate exercise induced dyspnoea. It is a sensitive diagnostic tool and should not be reserved for use in a highly athletic population. It appears to be particularly useful in patients diagnosed with EIB who are not responding to treatment. Therapeutic intervention in the form of physiotherapy once the diagnosis is made offers the potential for symptomatic improvement and the withdrawal of unneeded pharmacological agents.

\section{P48 PREVALENCE AND DETERMINANTS OF VITAMIN D DEFICIENCY IN ASTHMA PATIENTS}

${ }^{1}$ DA Jolliffe, ${ }^{1}$ AR Martineau, ${ }^{1} B M$ Maclaughlin, ${ }^{1}$ KK Kiplin, ${ }^{2}$ PMT Timms, ${ }^{1}$ CAM Mein, ${ }^{1}$ RW Walton, ${ }^{1}$ CJG Griffiths. ${ }^{1}$ Queen Mary University of London, London, UK; ${ }^{2}$ Homerton University Hospital, London, UK

\subsection{6/thoraxjnl-2014-206260.189}

Background Vitamin D deficiency has been reported to associate with susceptibility to acute respiratory infections and exacerbations in asthma patients. Studies investigating the prevalence and determinants of vitamin D deficiency among asthma patients in the UK are lacking.

Methods We conducted a cross-sectional study in297 asthma patients aged 16-78 years who participated in a clinical trial of vitamin D supplementation. Lifestyle and demographic data were collected by questionnaire and a blood sample was collected for analysis of serum 25-hydroxyvitamin D (25[OH]D) concentration and DNA extraction. Thirty-seven single nucleotide polymorphisms (SNP) in 13 vitamin D-related genes (DBP, DHCR7, CUBN, LRP2, CRTAM, LTA4H, CYP2R1, CYP3A4, CYP27A1, CYP27B1, CYP24A1, VDR, RXRA) were typed using Taqman allelic discrimination assays. Logistic regression was used to identify environmental and genetic factors associated with risk of vitamin D deficiency $(25[\mathrm{OH}] \mathrm{D}$ concentration $<50$ $\mathrm{nmol} / \mathrm{L}$ ).

Results Mean serum 25(OH)D concentration was $50.6 \mathrm{nmol} / \mathrm{L}$ (SD 24.9); 162/297 (54.5\%) participants were deficient. The following factors independently associated with increased risk of deficiency: BMI of $25.1-30 \mathrm{~kg} / \mathrm{m}^{2}$ (OR 2.20, $\left.\mathrm{p}=0.004\right)$ and $>30 \mathrm{~kg} / \mathrm{m}^{2}$ (OR 1.96, $\mathrm{p}=0.03$ ); blood draw during winter season (OR 3.26, p = 0.001); Fitzpatrick skin-type score of 1 ("extremely fair skin; always burn, never tan" - OR 5.15, $\mathrm{p}=0.02$ ). The following factors independently associated with decreased risk of deficiency: Caucasian ethnicity (OR 0.23, $\mathrm{p}=0.02) ;>2 \mathrm{~h}$ of sun exposure/day (OR 0.48, $\mathrm{p}=0.003)$; $100-400$ IU vitamin D supplement, daily (OR 0.22, $\mathrm{p}<0.001$ ); and use of a tanning bed in previous year (OR 0.20, $\mathrm{p}=0.006)$. The following genetic factors independently associated with increased risk of deficiency: carriage of the $G$ allele for DBP SNP rs4588 (GT genotype: OR 1.82, $\mathrm{p}=0.02$; GG genotype: OR 17.4, $\mathrm{p}=0.006)$; GT genotype for CYP2R1 SNP 
rs10500804 (OR 1.85, p = 0.02); AG genotype for CYP2R1 SNP rs10766197 (OR 1.82, $\mathrm{p}=0.03)$; AA genotype for VDR SNP rs7975232 (OR 2.15, p = 0.02).

Conclusions Over half of participating asthma patients were vitamin D deficient. Obesity, winter sampling, fair skin, and SNP in DBP, CYP2R1 and VDR genes were risk factors for deficiency. Caucasian ethnicity, sun seeking behaviour, modest daily supplement doses and recent tanning bed use were protective.

\section{P49 CAN THE ASTHMA CONTROL QUESTIONNAIRE (ACQ) AND/OR THE BLOOD EOSINOPHIL COUNT ACCURATELY DETECT SPUTUM EOSINOPHILIA?}

JR Anderson, DB Hodgson, EE Wilson, TW Harrison, DE Shaw. Nottingham Respiratory Research Unit, Nottingham, UK

\subsection{6/thoraxjnl-2014-206260.190}

Induced sputum differential cell counts provide important information about airway inflammation and future risk in asthma, but are not universally available. We set out to ascertain the sensitivity and specificity of the Juniper Asthma Control Questionnaire (ACQ) and/or the peripheral blood eosinophil count to detect a sputum eosinophil count $>3 \%$.

Methods We performed a retrospective, cross-sectional study of 165 subjects with asthma, aged 18-80, prescribed as-required bronchodilators, long-acting $\beta$-agonists, $0-4000$ mcg inhaled beclometasone diproprionate equivalent or maintenance oral steroids (0-20 mg prednisolone) from our database. Current smokers were excluded. Spirometry, FeNO at $50 \mathrm{ml}$ flow, sputum induction, Asthma Control Questionnaire (ACQ) and blood eosinophils (BEos) were recorded.

Induced sputum eosinophils (SEos) defined eosinophilic (EA, SEos $\geq 3 \%$ ) and non-eosinophilic (NEA, SEos $<3 \%$ ) groups. BEos, SEos and FeNO were $\log _{10}$ transformed and groups were compared with t-tests or Mann-Whitney-U using STATA and GraphPad. Receiver operating characteristic (ROC) curves determined cut-points of ACQ and BEos that identified SEos $\geq 3 \%$, and these were tested retrospectively in a second population of adults with asthma ( $\mathrm{n}=48,40 \% \mathrm{EA}$, mean $\mathrm{FEV}_{1} 82 \%$ predicted).

Results The $31 \%$ with EA had a lower $\mathrm{FEV}_{1} \%$ predicted and $\mathrm{FEV}_{1} / \mathrm{FVC}$ ratio, a higher FeNO, BEos and ACQ compared to NEA (Table 1). There was a significant correlation between ACQ and sputum eosinophils (Pearson r 0.32, $\mathrm{p}<0.0001$ ).

The optimal cut-points of ACQ and BEos identifying a SEos of $3 \%$ were an ACQ $>1.57$ (sensitivity 55\%, specificity 78\%) and BEos $\geq 0.22 \times 10^{9} / \mathrm{L}$ (sensitivity $84 \%$ and specificity $68 \%$ ) respectively. Individuals with both ACQ of $\geq 1.57$ AND a BEos of $\geq 0.22$ the sensitivity was $45 \%$ and specificity of $100 \%$ for a SEos of $3 \%$.

Testing in the second population the ACQ $\geq 1.57$ had a sensitivity $47 \%$ and specificity $86 \%$ for SEos $>3 \%$ while BEos $\geq 0.22$ had sensitivity $68 \%$ and specificity $45 \%$. The combination of ACQ $\geq 1.57$ AND BEos $\geq 0.22$ had a lower sensitivity of $37 \%$

\begin{tabular}{|c|c|c|c|c|}
\hline & All & Sputum eosinophils $<3 \%$ & Sputum eosinophils $>3 \%$ & $p$ value \\
\hline Number observations & $\mathrm{n}=165$ & $\mathrm{n}=114(69 \%)$ & $\mathrm{n}=54(31 \%)$ & \\
\hline Age (years) & $56.2 \pm 13.4$ & $57.4 \pm 13.75$ & $53.5 \pm 12.2$ & 0.081 \\
\hline \multicolumn{5}{|l|}{ Gender } \\
\hline Male $n$ (\%) & $81(49.1 \%)$ & $53(46.5 \%)$ & $28(54.9 \%)$ & \\
\hline Female $n(\%)$ & $84(50.9 \%)$ & $61(53.5 \%)$ & $23(45.1 \%)$ & - \\
\hline FEV $_{1}$ (Litres) & $2.39 \pm 0.85$ & $2.46 \pm 0.87$ & $2.23 \pm 0.79$ & 0.12 \\
\hline $\mathrm{FEV}_{1} \%$ predicted & $80.5 \pm 20.7$ & $83.54 \pm 19.4$ & $73.7 \pm 23.2$ & $0.005^{*}$ \\
\hline FVC (Litres) & $3.46 \pm 1.03$ & $3.49 \pm 1.06$ & $3.36 \pm 0.95$ & 0.46 \\
\hline FVC $\%$ predicted & $95.1 \pm 18.8$ & $96.9 \pm 17.5$ & $91.0 \pm 21.09$ & 0.062 \\
\hline $\mathrm{FEV}_{1} / \mathrm{FVC}$ & $68.7 \pm 9.9$ & $70 \pm 9.8$ & $65.7 \pm 9.4$ & $0.008^{*}$ \\
\hline Body-mass index $\left(\mathrm{Kg} / \mathrm{m}^{2}\right)^{+}$ & $28.6 \pm 5.1$ & $28.8 \pm 4.0$ & $26.9 \pm 3.0$ & 0.54 \\
\hline \multicolumn{5}{|l|}{ History of smoking } \\
\hline (Pack-years) & 0 & 0. & 0 & \\
\hline Median (range) & $(0,20)$ & $(0,20)$ & $(0,15)$ & $0.87^{\dagger}$ \\
\hline Daily inhaled corticosteroid dose (Becolmetasone diproprionate equivalent [mcg/day]) & 400 & 400 & 800 & \\
\hline Median (range) & $(0,3200)$ & $(0,3200)$ & $(0,3200)$ & $0.05^{\dagger}$ \\
\hline Oral Prednisolone & 0 & 0 & 0 & \\
\hline Median (range) & $(0,20)$ & $(0,15)$ & $(0,20)$ & $\cdot$ \\
\hline Juniper $A C Q^{\#}$ score & $1.4 \pm 1.0$ & $1.1 \pm 0.9$ & $1.9 \pm 1.2$ & $<0.001^{*}$ \\
\hline Exhaled nitric oxide FeNO at 50ml flow (ppb) Geometric mean (95\% Cl) & $25.7(22.9,28.8)$ & $20.0(17.8,22.9)$ & $44.7(35.5,56.23)$ & $<0.001^{*}$ \\
\hline \multicolumn{5}{|l|}{ Sputum differential eosinophil count \% } \\
\hline Geometric mean $(95 \%$ Cl) & $1.24(0.95,1.62)$ & $0.47(0.39,0.55)$ & $11.0(8.3,14.13)$ & $<0.001^{*}$ \\
\hline \multicolumn{5}{|l|}{ Blood eosinophils $\left(x 10^{9} / L\right)$} \\
\hline Geometric mean & $0.24(0.22,0.28)$ & $0.19(0.18,0.21)$ & $0.43(0.36,0.5)$ & $<0.001^{*}$ \\
\hline $\begin{array}{l}\text { Arithmetic mean values reported as mean unless specified } \\
\pm \text { Standard deviation } \\
\text { Geometric means are reported with a } 95 \% \text { Confidence Interval (CI) } \\
\text { The difference between means compared with } \mathrm{t} \text {-test unless specified with } \dagger \\
\text { \# Juniper Asthma Control Questionnaire- A validated questionnaire providing a numerical asses } \\
\text { to } 6 \text { (poorly controlled) } \\
\dagger \text { Mann-Whitney U } \\
{ }^{*} \mathrm{p}<0.05 \\
\mathrm{FEV} \mathrm{F}_{1} \text {. Forced expiratory volume in one second } \\
\text { FVC- Forced vital capacity } \\
\text { ppb- Parts per billion }\end{array}$ & th of asthma con & ver the preceding 7 days. T & mean score ranges from 0 (fu & controlled) \\
\hline
\end{tabular}

